\title{
Powder and Solvent for Nebulizer Solution Dosage Form
}

National Cancer Institute

\section{Source}

National Cancer Institute. Powder and Solvent for Nebulizer Solution Dosage Form. NCI

Thesaurus. Code C149788.

Powder and solvent intended for the preparation of a nebulizer solution by dissolving the powder in the solvent. 